\title{
The effect of thermal treatments on the mechanical and electrical properties of nickel-coated carbon fibre composites
}

\author{
Boguslaw Pierozynski \\ University of Warmia and Mazury in Olsztyn, Department of Chemistry, Faculty of Environmental Management and \\ Agriculture, Plac Łódzki 4, 10-957 Olsztyn, Poland, e-mail: bogpierozynski@yahoo.ca or boguslaw.pierozynski@uwm.edu.pl
}

\begin{abstract}
Nickel-coated carbon fibre (NiCCF) composites may find technological applications within many industrial sectors, including: laptop computers, automotive and military industries. Typically, these applications require that NiCCF be subjected to extensive material processing; thus, optimization of mechanical (and electrical) properties for this material at the stage of its production is of significant importance. The present paper reports the application of specific, high-temperature heat treatments to laboratory-produced $12 \mathrm{~K} 50 \mathrm{NiCCF}$ material, carried-out in order to improve the ductility and interfacial adhesion of electrodeposited Ni coating to the surface of carbon fibre substrate.
\end{abstract}

Keywords: nickel-coated carbon fibre; NiCCF; interfacial adhesion; electrical resistivity.

\section{INTRODUCTION}

One of the most important applications for carbon fibre $(\mathrm{CF})$ and nickel-coated carbon fibre (NiCCF) materials is their utilization in electrostatic dissipation (ESD) and electromagnetic interference (EMI) shielding techniques. These technologies are especially important for automotive, cell-phone, laptop computer and military industry markets $\mathbf{1}^{\mathbf{1 - 6}}$. Most of the materials which are used for EMI/ESD applications are conductive thermoplastic composites, which may contain a variety of electrically conductive fillers, including metal fibres and metal-coated carbon fibres. Electrically conductive thermoplastics are typically produced through an injection-moulding process, where the conductive filler is introduced to the moulding machine, either in a chopped form or as the so-called long fibre- reinforced thermoplastic pellets (LFRTP) ${ }^{7-15}$. Unfortunately, the moulding process is fairly destructive to the conductive additives, especially when the fillers are themselves fragile materials, such as the ultra-thin metal filaments, carbon fibres or metal-coated carbon fibre materials. When the conductive filler becomes significantly damaged, such-produced thermoplastic materials provide the appreciably lower levels of shielding effectiveness (SE), as compared to those obtained with the largely undamaged filler(s). One way to deal with this problem is to optimize the plastic processing technology (including the operational conditions for the injection moulding process) and another (parallel) action, should involve optimization of the parameters for the conductive filler.

This work is primarily concerned with the improvement of mechanical properties (through the application of selected heat treatments) for a $12 \mathrm{~K} 50 \mathrm{NiCCF}$ composite (12.000 filament tow of about $7.5 \mu \mathrm{m}$ diameter for each filament and ca. $50 \mathrm{wt} . \% \mathrm{Ni}$ ), with respect to the ductility of $\mathrm{Ni}$ and its interfacial adhesion to the surface of carbon fibre strands. In addition, an influence of thermal processing on the electrical resistivity parameter for the NiCCF composite was investigated.

\section{EXPERIMENTAL}

All the examined $12 \mathrm{~K} 50 \mathrm{NiCCF}$ samples were produced by the electrodeposition of $\mathrm{Ni}$ onto a de-sized (through heat-treatment at $350{ }^{\circ} \mathrm{C}$, carried-out for 4 hours in low oxygen/inert gas atmosphere) Hexcel 12K AS4 polyacrylonitrile (PAN)-based carbon fibre tow ${ }^{16}$ product, from a typical Watts nickel plating bath ${ }^{17},{ }^{18}$. The electrodeposition trials took place in a beaker-made cell, where ca. $20 \mathrm{~cm}$ long CF samples were subjected to dc plating, in a stationary arrangement (all details of this process and those that concern the characterization of the NiCCF material are given in Ref. 19).

A small, high-temperature tube furnace with a single heating zone was used to carry-out all the heat-treatment experiments. The working gas atmosphere inside the furnace was 50/50 vol. $\% \mathrm{H}_{2}+\mathrm{Ar}$ (both high-purity gas products were pumped in at $\left.0.5 \mathrm{dm}^{3} \mathrm{~min}^{-1}\right)$, where $\mathrm{H}_{2}$ was used to avoid high temperature oxidation of NiCCF. The furnace operation procedure was as follow:

a) furnace purging with $\operatorname{Ar}(30 \mathrm{~min})$

b) heating system turned on

c) $\mathrm{H}_{2}$ pressure turned on (upon stabilization of the set annealing temperature)

d) introduction of NiCCF samples $(18 \mathrm{~cm}$ long) into the hot zone of the furnace

e) annealing of the NiCCF samples (carried-out for 10 min, over the temperature range between 300 and $900^{\circ} \mathrm{C}$ )

f) heating system turned off

g) cooling of the NiCCF samples ( $c a$. several hours)

$-\mathrm{H}_{2}$ pressure turned off (at the hot zone temperature of $200^{\circ} \mathrm{C}$ )

- Ar purging stopped (at the hot zone temperature of $\left.100^{\circ} \mathrm{C}\right)$

h) removal of the NiCCF samples from the furnace (at near room temperature).

In addition, a series of heat-treatment experiments with fast quenching of the NiCCF tow samples was also carried-out. Firstly, an $18 \mathrm{~cm}$ long NiCCF sample was held for $10 \mathrm{~min}$ in an insulated from the furnace's hot zone chamber, in a reducing atmosphere of 50/50 vol. $\% \mathrm{H}_{2}$ + Ar. Following this pre-conditioning step, the sample was quickly transferred into the hot furnace zone (also filled with $\mathrm{H}_{2} / \mathrm{Ar}$ gas mixture), where it remained for $60 \mathrm{~s}$. Then, the sample was quickly returned to the cooling zone (at ca. $30^{\circ} \mathrm{C}$ ), where it was kept for additional $60 \mathrm{~s}$, before being finally removed back to air. Annealing temperatures in the hot furnace zone ranged from 200 to $800^{\circ} \mathrm{C}$ (with $100^{\circ} \mathrm{C}$ increments). 
Electrical resistivity measurements were performed on the selected samples of the $12 \mathrm{~K} 50 \mathrm{NiCCF}$ tow, by measuring the voltage drop at the constant applied current $(100 \mathrm{~mA})$, over a distance of $15-20 \mathrm{~cm}$. Both electrical contact points on the NiCCF samples were silver-painted, in order to reduce the electrical contact resistance. Fibre resistivity was then calculated from equation 1 below:

$\xi=\frac{V \times S a}{I \times l} \quad[\Omega \mathrm{cm}]$

where:

$\xi$ - is calculated resistivity of the NiCCF tow sample $[\Omega \mathrm{cm}]$

$\mathrm{V}$ - is measured voltage [mV]

$\mathrm{S}_{\mathrm{a}}-$ is sample's cross sectional area $\left(5.3 \times 10^{-3} \mathrm{~cm}^{2}\right)$

$\mathrm{I}-$ is applied current $(100 \mathrm{~mA})$

1 - is sample's length $(15-20 \mathrm{~cm})$.

In addition, a simple, SEM (scanning electron microscopy)-supported knot test was used to qualitatively evaluate the strength of interfacial adhesion of $\mathrm{Ni}$ (potentially, also its ductility) to the surface of CF filaments. The knot test ${ }^{20,21}$ is a mechanical bending experiment, in which a piece of NiCCF tow is bent sharply enough (a constant load of $500 \mathrm{~g}$ for $5 \mathrm{~s}$ was applied to tie all the NiCCF knots in this work) to break the metal coating on the tension side of the bend. Then, the knots are qualitatively examined and compared by the SEM method.

\section{RESULTS AND DISCUSSION}

\section{SEM evaluations}

Figure 1 below shows the SEM micrographs for a knottied, as received laboratory-produced $12 \mathrm{~K} 50 \mathrm{NiCCF}$ sample, where the mechanical bending force applied to the NiCCF tow led to significant Ni breaking and also partial delamination of the metal coating. However, application of a high-temperature $\left(500\right.$ and $\left.600^{\circ} \mathrm{C}\right)$ heat-treatment to $\mathrm{NiCCF}$ tow samples does seem to result in somewhat increased ductility of the coating, where no significant $\mathrm{Ni}$ delamination (or flaking) can be observed for a similar knot-test experiment, as comparatively shown in Fig. 2. Further increase in the annealing temperature caused

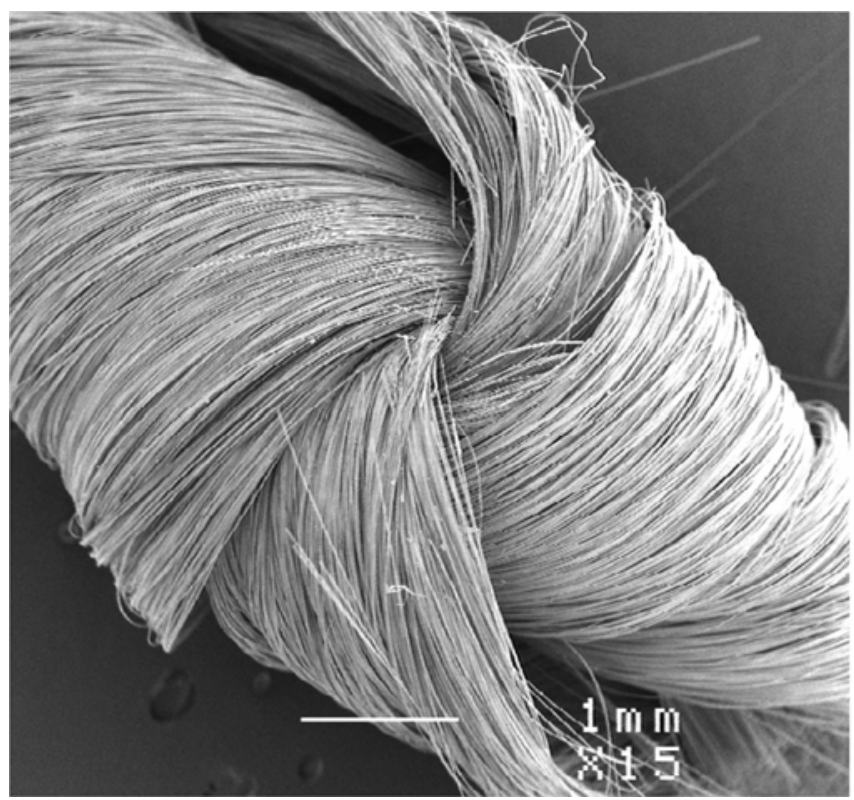

gradual deterioration of the NiCCF composite, evidenced by increased brittleness and weakened flexibility of the material. In an extreme case (for the annealing temperature of $900^{\circ} \mathrm{C}$ ), SEM micrograph pictures disclosed significant morphology changes (see Fig. 3 below), which were revealed in the observable migration of $\mathrm{Ni}$ into the core of carbon fibre filaments. Such-treated NiCCF tow samples were very brittle, so that no knot testing (or electrical resistivity measurements) could have been performed. It is possible that the temperature of $900^{\circ} \mathrm{C}$ is sufficiently high to initiate the process of carbon fibre graphitization, which is well-known ${ }^{22}-24$ to be highly catalyzed by transition type metals, such as nickel. Furthermore, the knot-tests conducted for NiCCFs heat-treated at temperatures below $500^{\circ} \mathrm{C}$ did not reveal any improvement with respect to adhesion of nickel coating to carbon fibre surface (as compared to that shown in Fig. 1 for as received $\mathrm{NiCCF}$ tow).

On the other hand, short-time (60 s) annealing experiments (which followed fast cooling of heat-treated NiCCF tow samples) were performed in order to simulate a continuous heat-treatment process. In fact (understandably),

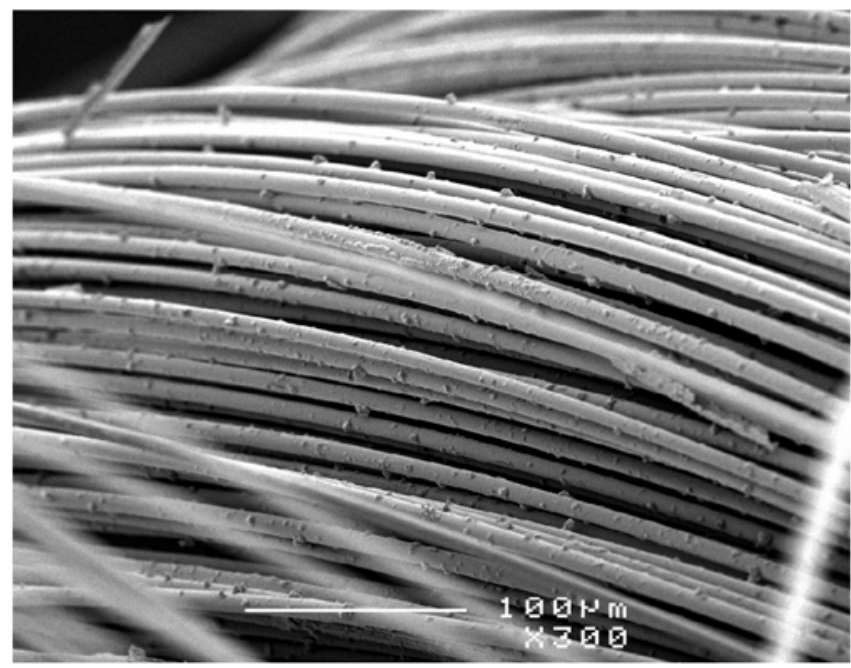

Figure 2. SEM micrograph picture of the knot-tied, heattreated at $600^{\circ} \mathrm{C} 12 \mathrm{~K} 50 \mathrm{NiCCF}$ tow sample (at $c a$. 42 wt. $\% \mathrm{Ni})$, taken at 300 magnification

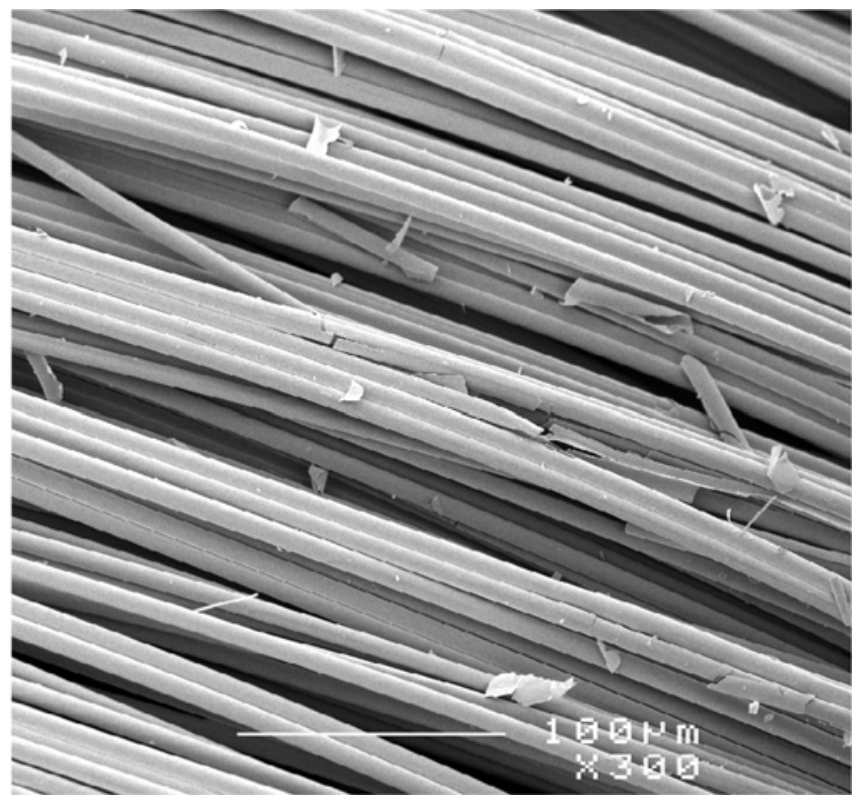

Figure 1. SEM micrograph pictures of the knot-tied, as received $12 \mathrm{~K} 50 \mathrm{NiCCF}$ tow sample (at ca. $45 \mathrm{wt} \% \mathrm{Ni}$ ), taken at 15 and 300 magnifications 

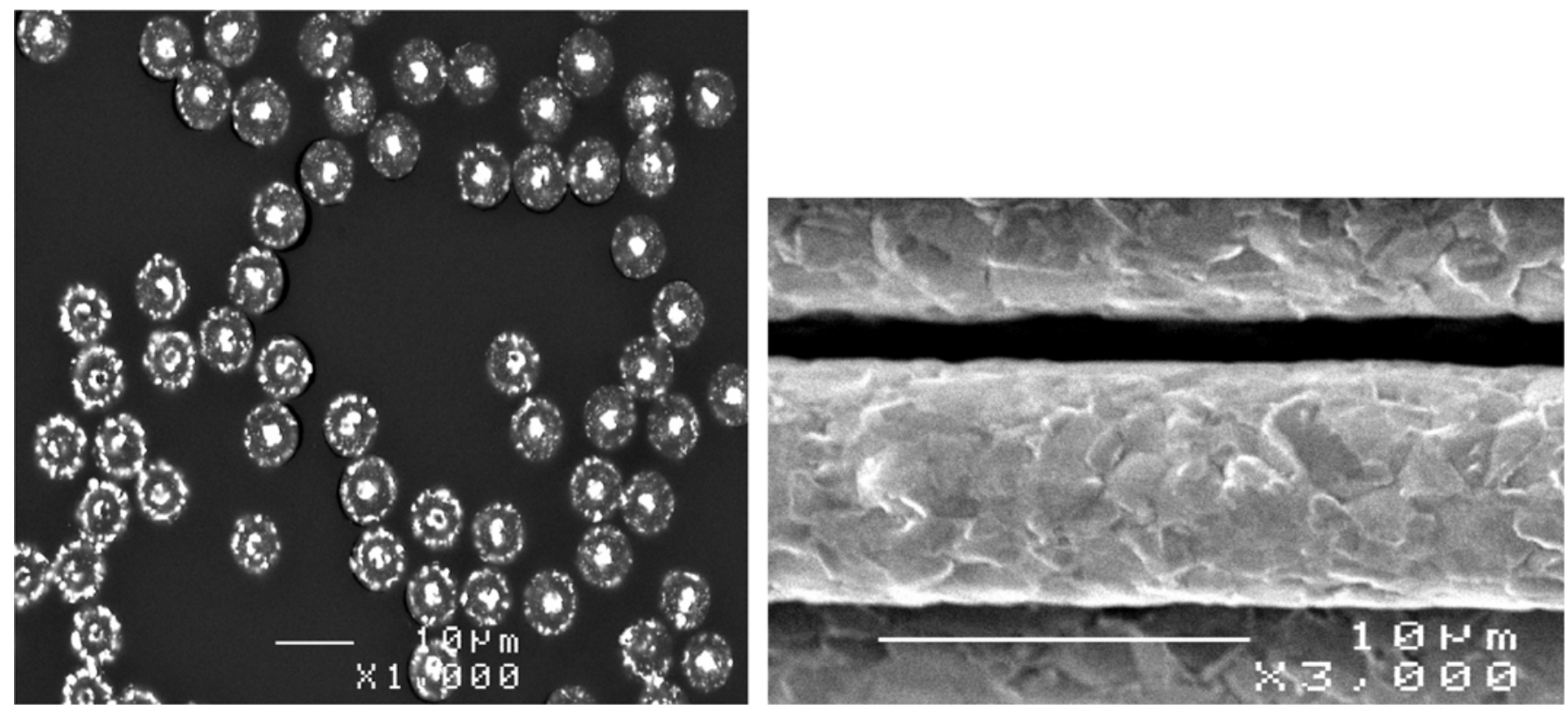

Figure 3. SEM micrograph (cross-sectional and side view) pictures of the heat-treated at $900^{\circ} \mathrm{C} 12 \mathrm{~K} 50 \mathrm{NiCCF}$ tow sample (at ca. 45 wt. $\% \mathrm{Ni}$ ), taken at 1.000 and 3.000 magnifications

only very short annealing time could be considered viable from the technological point of view. For the experiments performed over the temperature range: $400-800^{\circ} \mathrm{C}$, the effect of thermal treatment is revealed (see SEM micrograph picture in Fig. 4 below) in considerable Ni flaking and peeling off the carbon fibre surface. The above is likely the effect of the thermal expansion coefficient (TEC) mismatch between $\mathrm{Ni}$ and $\mathrm{CF}$ materials, in addition to the relatively weak interfacial Ni-to-CF bonding. Conversely, practically no deterioration of the NiCCF composite was observed for the annealing temperatures below $400^{\circ} \mathrm{C}$. Also, a significant increase in the grain size of the nickel deposit was observed for all NiCCF samples, which were heat-treated at 700 and $800^{\circ} \mathrm{C}$, as compared to un-treated fibre tow samples (compare Fig. 5a with Fig. 5b, correspondingly). An average, estimated by the PXRD (powder x-ray diffraction) method grain size of Ni deposit for as received $\mathrm{NiCCF}$ came to about $25 \mathrm{~nm}^{19}$.

\section{Electrical resistivity measurements}

The electrical resistivity parameter for as received $\mathrm{NiCCF}$ tow samples varied between 110 and $115 \mu \Omega \mathrm{cm}$. High temperature heat-treatments applied to the NiCCF

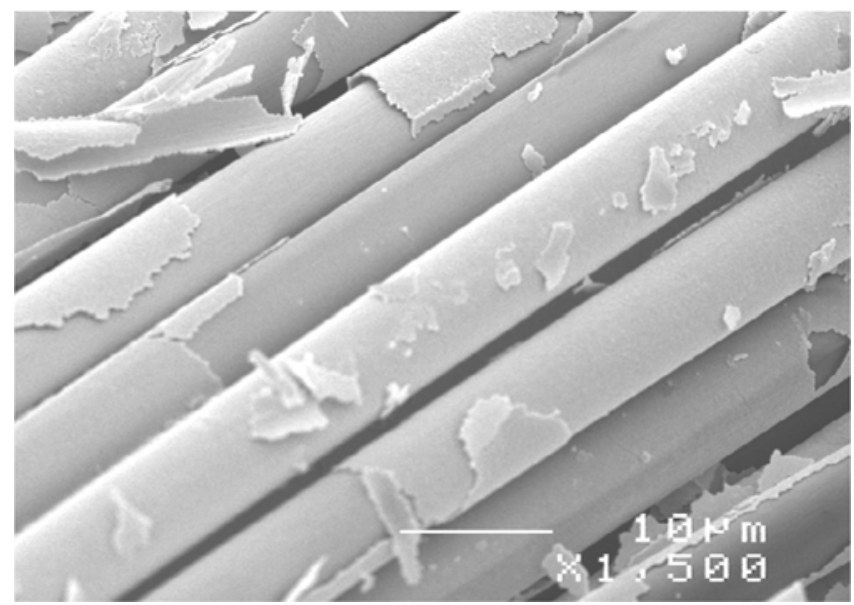

Figure 4. SEM micrograph picture of short-time $(60 \mathrm{~s})$ heattreated $\left(\right.$ at $600^{\circ} \mathrm{C}$ ) $12 \mathrm{~K} 50 \mathrm{NiCCF}$ tow sample (at $c a .45$ wt. $\% \mathrm{Ni})$, taken at 1.500 magnification
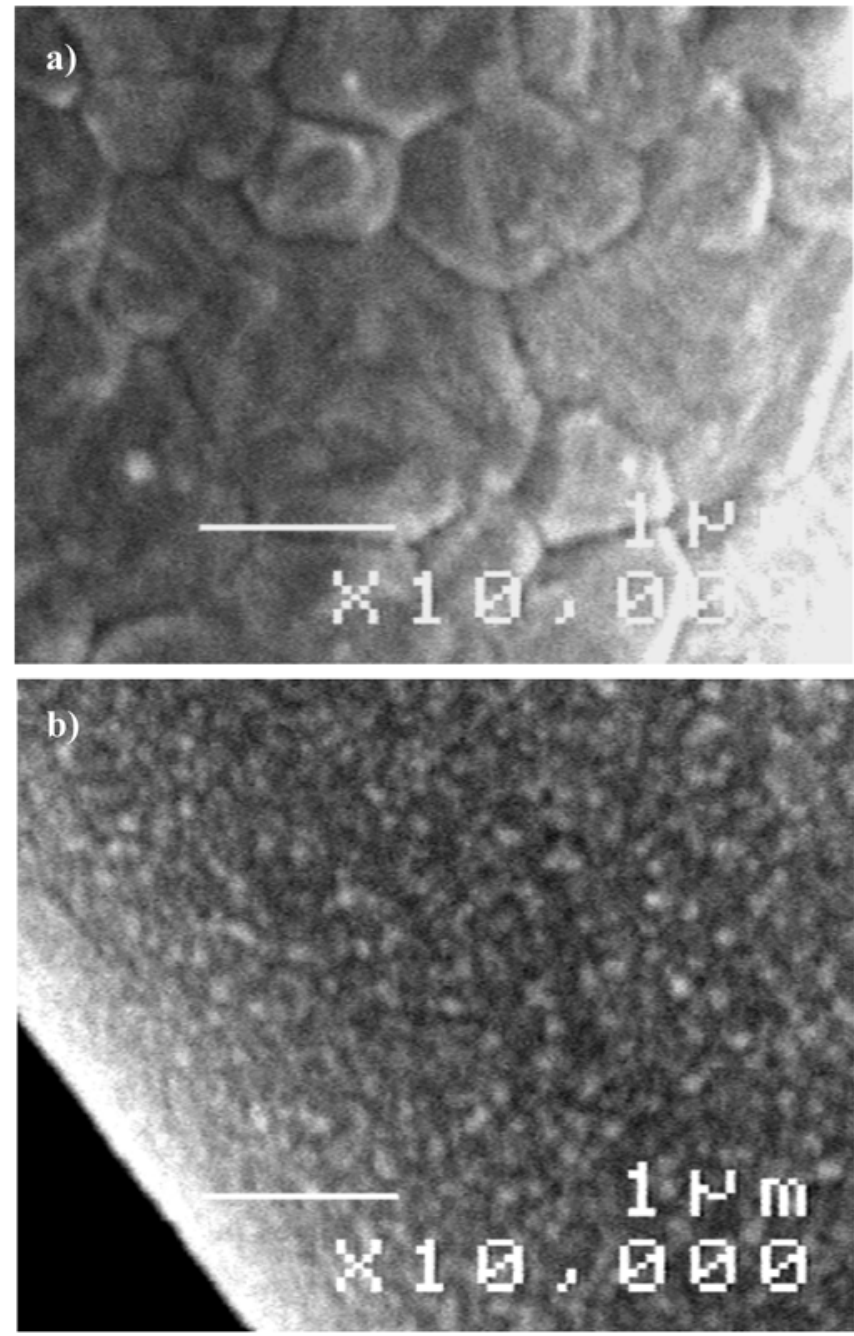

Figure 5. SEM micrograph pictures of short-time $(60 \mathrm{~s})$ heattreated $\left(\right.$ at $\left.700^{\circ} \mathrm{C}\right) 12 \mathrm{~K} 50 \mathrm{NiCCF}$ tow sample, at $c a$. 45 wt. \% $\mathrm{Ni}$ (a) and as received $12 \mathrm{~K} 50 \mathrm{NiCCF}$ sample (b), showing the effect of high-temperature treatment on the grain size of the metal deposit (taken at 10.000 magnification) 


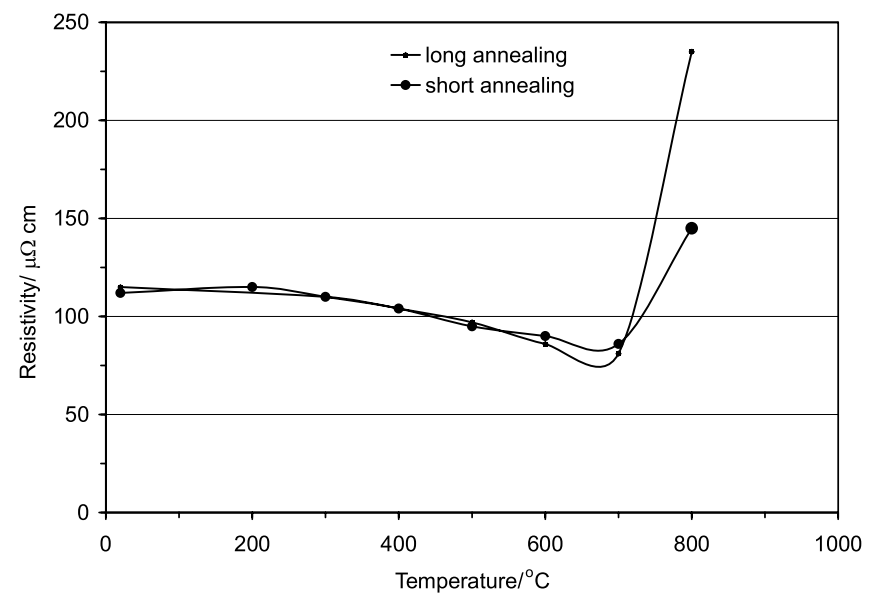

Figure 6. Electrical resistivity vs. annealing temperature for heat-treated 12K50 laboratory-electrodeposited $\mathrm{NiCCF}$ tow samples [obtained results were averaged $(c a . \pm 5 \%)$, based on the resistivity measurements conducted for three heat-treated NiCCF samples at each temperature]

tow samples (over the temperature range: $400-700^{\circ} \mathrm{C}$ ) led to a significant reduction (by nearly $30 \%$ ) of the resistivity parameter, as shown in Fig. 6 below. The above was consistent for both the long-time, as well as the fast cooling heat-treatments, which phenomenon is very likely the effect of a considerably increased $\mathrm{Ni}$ grain size, as shown in Fig. 5a above.

Conversely, no explicit effect on the fibre electrical resistivity parameter was observed for the annealing temperatures below $400^{\circ} \mathrm{C}$. Furthermore, heat-treatments performed at temperatures above $600^{\circ} \mathrm{C}$ (see p. 3.1) caused substantial mechanical deterioration of the nickel-coated carbon fibre material. Thus, the exhibited levels of electrical resistivity were in these cases on the order of those (or even significantly higher) that were reported for the un-treated NiCCF composite (see again Fig. 6).

\section{CONCLUSIONS}

High temperature heat-treatment is an effective method for the improvement of Ni-to-CF interfacial properties and electrical conductivity for nickel-coated carbon fibre composite material. However, selection of the right temperature range and the sample's residence time within the furnace's hot zone do seem essential. It was confirmed in this work that extremely high temperatures could lead to severe deterioration and eventually to mechanical disintegration of the fibre material. Thus, if the process is to be carried-out continuously, then one should rather concentrate on the optimization of short-time annealing/fast NiCCF cooling experiments, which combination is the only viable option for a commercially run process.

\section{LITERATURE CITED}

1. Chung, D.D.L. (2004). Electrical applications of carbon materials. J. Mater. Sci. 39(8), 2645-2661. DOI: 10.1023/ B:JMSC.0000021439.18202.ea.

2. Markham, D. (2000). Shielding: quantifying the shielding requirements for portable electronic design and providing new solutions by using a combination of materials and design. Mater. Design 21(1), 45-50. DOI: 10.1016/S0261-3069(99)00049-7.
3. Tzeng, S.S. \& Chang, F.Y. (2001). EMI shielding effectiveness of metal-coated carbon fiber-reinforced ABS composites. Mater. Sci. Eng. A 302(2), 258-267. DOI: 10.1016/ S0921-5093(00)01824-4.

4. Chung, D.D.L. (2001). Electromagnetic interference shielding effectiveness of carbon materials. Carbon 39(2), 279285. DOI: 10.1016/S0008-6223(00)00184-6.

5. Fu, S.Y., Lauke, B., Mader, E., Yue, C.Y. \& Hu, X. (2000). Tensile properties of short-glass-fiber- and short-carbon-fiber-reinforced polypropylene composites. Composites: Part A 31(10), 1117-1125. DOI: 10.1016/S1359-835X(00)00068-3.

6. Donnet, J.B. \& Bansal, R.C. (1990). Carbon Fibers. New York, USA: Marcel Dekker, Inc.

7. Soens, L.J. (1987). U.S. Patent No. 4,664,971. Washington, D.C.: U.S. Patent and Trademark Office.

8. Adriaensen, L. \& Verhaeghe, F. (1988). U.S. Patent No. 4,788,104. Washington, D.C.: U.S. Patent and Trademark Office.

9. Soens, L.J. (1995). U.S. Patent No. 5,397,608. Washington, D.C.: U.S. Patent and Trademark Office.

10. Cogswell, F.N., Hezzell, D.J. \& Williams, P.J. (1985). U.S. Patent No. 4,559,262. Washington, D.C.: U.S. Patent and Trademark Office.

11. Cogswell, F.N., Hezzell, D.J. \& Williams, P.J. (1991). U.S. Patent No. 5,019,450. Washington, D.C.: U.S. Patent and Trademark Office.

12. Cogswell, F.N., Hezzell, D.J. \& Williams, P.J. (1993). U.S. Patent No. 5,213,889. Washington, D.C.: U.S. Patent and Trademark Office.

13. Iyer, S., Dzal, L.T. \& Jayaraman, K. (1992). U.S. Patent No. 5,102,690. Washington, D.C.: U.S. Patent and Trademark Office.

14. Working, D. (1993). U.S. Patent No. 5,213,843. Washington, D.C.: U.S. Patent and Trademark Office.

15. Bellemare, D.J. (1997). U.S. Patent No. 5,639,307. Washington, D.C.: U.S. Patent and Trademark Office.

16. Hexcel Corporation. HexTow ${ }^{T M}$ AS4C Carbon Fiber. Product Data. Retrieved April 21, 2010, from http://www.hexcel.com.

17. Lowenheim, F.A. (2000). In M. Schlesinger \& M. Paunovic (Eds.), Modern Electroplating (4 ${ }^{\text {th }}$ Ed.). New York, USA: John Wiley \& Sons, Inc.

18. Di Bari, G. (2002). Nickel plating. Metal Finishing 100(1), 257-274. DOI: 10.1016/S0026-0576(02)82027-X.

19. Pierozynski, B. \& Smoczynski, L. (2008). Electrochemical corrosion behavior of nickel-coated carbon fiber materials in various electrolytic media. J. Electrochem. Soc. 155(8), C427C436. DOI: 10.1149/1.2936994.

20. Ulcay, Y. \& Altun, S. (2004). Effects of gamma irradiation on some mechanical properties of novoloid fibers. Fibers and Polymers 5(2), 156-159. DOI: 10.1007/BF02902931.

21. ASTM Standards. (2010). Standard test method for tensile properties of yarns by the single-strand method. ASTM D2256/D2256M-10e1. ASTM International. West Conshohocken (PA). DOI: 10.1520/D2256_D2256M-10E01.

22. Tzeng, S.S. (2006). Catalytic graphitization of electroless Ni-P coated PAN-based carbon fibers. Carbon 44, 1986-1993. DOI: 10.1016/j.carbon.2006.01.024.

23. Zhou, H., Yu, Q., Peng, Q., Wang, H., Chen, J. \& Kuang, Y. (2008). Catalytic graphitization of carbon fibers with electrodeposited Ni-B alloy coating. Mater. Chem. Phys. 110, 434-439. DOI: 10.1016/j.matchemphys.2008.02.033.

24. Maldonado-Hodar, F.J., Moreno-Castilla, C., RiveraUtrilla, J., Hanzawa, Y. \& Yamada, Y. (2000). Catalytic graphitization of carbon aerogels by transition metals. Langmuir 16(9), 4367-4373. DOI: 10.1021/la991080r. 